\title{
Apropriação da Pronúncia do Jnglês por Professores em Formação Inicial
}

English Pronunciation Acquisition by In-Service Teachers

Neide Cesar CRUZ *

Resumo: Este estudo investiga a apropriação da pronúncia do inglês por professores em formação inicial, de uma universidade pública, da região nordeste do Brasil. A coleta dedados ocorreu durante a disciplina Fonética da língua inglesa, através de dois instrumentos: notas reflexivas e discussão em grupo áudio gravada. Os resultados sugerem que os alunos-professores descobriram novas formas de pronunciar e valorizam a pronúncia do falante nativo como modelo a ser seguido. Palavras-chave: Pronúncia. Apropriação. Professores em formação inicial.

Abstract: This study investigates in-service teachers' pronunciation acquisition, at a university in the northeast of Brazil. The data was collected during the English Phonetics course, through two instruments: reflective notes and a recorded group interview. The results suggest that the participants discovered new ways of pronouncing words and value the native speaker pronunciation as a model to be followed.

Key-words: Pronunciation. Acquisition. In-service teachers.

\section{Introdução}

Pronúncia, no contexto de ensino de uma língua estrangeira, é

\footnotetext{
* Doutorado em Letras (Inglês e Literatura Correspondente) pela Universidade Federal de Santa Catarina (2004). Mestrado em Letras pela Universidade Federal da Paraíba (1991). Atualmente é professora adjunto da Universidade Federal de Campina Grande. Contato: neidecruz@uol.com.br
} 
definida por Dalton e Seildhofer (1995, p. 3) de duas formas: (1) a produção e a percepção dos sons de uma determinada língua; e (2) a combinação de códigos para tornar a comunicação nessa língua possível. Um grande número de variáveis influencia a aprendizagem da pronúncia, tais como a atitude do aprendiz em relação à língua-alvo e aos falantes dessa língua, a motivação para aprender e a habilidade fonética. Devido a essas variáveis, "nunca pode haver uma relação direta entre o que é ensinado e o que é aprendido" 1 (DALTON; SEILDHOFER, 1995, p. 72).

Concordo com a ausência dessa relação direta, e considero que a mesma impede que professores-formadores de língua inglesa identifiquem, não só as dificuldades e facilidades referentes à pronúncia dos seus alunos-professores, mas também os fatores que influenciam o desenvolvimento fonético de cada um. A impossibilidade dessa identificação, juntamente com o meu interesse pelo ensino e aprendizagem da pronúncia do inglês, levou-me a realizar este estudo que focaliza a pronúncia de professores de inglês em formação inicial. Especificamente, o estudo investiga como ocorre a apropriação da pronúncia do inglês por professores em formação inicial, sob o prisma desses alunos-professores.

\section{Metodologia}

\subsection{Contexto do estudo}

O contexto do estudo foi a disciplina Fonética da Língua Inglesa, ministrada por mim, oferecida em um curso de Letras/Inglês, de uma universidade pública da região nordeste do Brasil. ${ }^{2}$ A disciplina teve a duração de 60 horas, com 2 encontros semanais de 2 horas.

\footnotetext{
1 "there can never be a one-to-one relationship between what is taught and what is learnt"

${ }^{2}$ Não mencionarei o semestre em que a disciplina foi oferecida para preservar a identidade dos participantes.
} 
O conteúdo foi dividido em três partes. A primeira focalizou a descrição do sistema sonoro do inglês, de forma teórica e prática. $\mathrm{O}$ aspecto teórico envolveu a descrição de grupos de sons - consoantes, vogais, ditongos e acentuação de palavras - com base em Avery e Ehrlich (1994), O’Connor (1999), Roach (2002) e Silva (2005). Em seguida, a identificação dos sons considerados difíceis para aprendizes brasileiros produzirem e que, possivelmente, podem constituir dificuldades de pronúncia para alunos-professores, foi discutida, com base em cinco estudos: Mascherpe (1970), Lessa (1985), Lieff e Nunes (1993), Rebello (1997) e Baptista (2001). Esses estudos apresentam os sons considerados difíceis para aprendizes brasileiros produzirem e os sons que esses aprendizes tendem a pronunciar devido a essas dificuldades.

O aspecto prático refere-se ao treino individual da percepção e da produção dos grupos de sons estudados, com atividades e áudios extraídos de O’Connor e Fletcher (1989), Hewings (1993), O’Connor (1999) e Schumacher, White e Zanettini (2002). Os alunos-professores foram solicitados a discriminar e a produzir sons em palavras, sentenças e em contextos maiores, e, posteriormente, a identificar em suas próprias produções a possível ocorrência de inadequações de pronúncia. Esse treino foi possível, uma vez que a disciplina Fonética da Língua Inglesa é ministrada em um Laboratório de Línguas.

A segunda parte do conteúdo refere-se à discussão da inteligibilidade da pronúncia de aprendizes brasileiros de inglês, através de resultados de pesquisas em inteligibilidade. Essa discussão focalizou os desvios de pronúncia que afetam a inteligibilidade da fala de aprendizes brasileiros de inglês, tanto para ouvintes nativos, com base em Cruz (2005a), Cruz (2005b) e Cruz (2006a), como para ouvintes de nacionalidades diferentes, ou seja, no contexto de Inglês Língua Franca (ILF), com base em Cruz (2006b) e Silva (1999).

Finalmente, a terceira parte envolveu atividades práticas de percepção de outros sotaques da língua inglesa: escocês, irlandês e indiano. Os diálogos envolvendo falantes desses sotaques foram extraídos de Collie e Slater (1993). Essa etapa foi incluída, uma vez que os livros que oferecem as atividades práticas de pronúncia realizadas no curso utilizam a variedade britânica denominada RP (Received 
Pronunciation) e a variedade americana denominada GA (General American). ${ }^{3}$

\subsection{Participantes}

Sete alunos cursaram a disciplina Fonética da língua inglesa, e aceitaram participar deste estudo. Quatro são do sexo masculino e três do sexo feminino. Os participantes tinham idades variando entre $19 \mathrm{e}$ 24 anos. Dois lecionavam inglês em curso de idiomas, e dois em escola particular. Três deles não lecionavam. Nenhum deles havia tido experiência com o inglês fora do Brasil. Quatro tiveram a oportunidade de estudar em uma escola de idiomas.

\subsection{Coleta de dados}

Dois instrumentos foram utilizados na coleta de dados: notas reflexivas $^{4}$ e discussão em grupo gravada em áudio.

\section{Notas reflexivas}

Sugeri aos alunos, no primeiro dia de aula, uma atividade que deveria ser realizada durante o curso. Expliquei que eles deveriam escrever notas, registrando suas reflexões sobre o curso. Essas notas deveriam conter uma avaliação dos seus desempenhos nas atividades teóricas e práticas, indicando os aspectos positivos e negativos, suas dificuldades e facilidades. Além disso, sugeri que registrassem como poderiam usar os conteúdos estudados em suas atividades como professores, e que comentassem qualquer outro aspecto do curso que desejassem.

3 'Received' de RP significa 'geralmente aceito' "received (generally 'accepted')" (WELLS, 1998, p. 117) e 'General' de GA tem esse termo por não ser um sotaque uniforme "is by no means a uniform accent" (WELLS, 1998, p. 118). Mais informações a respeito da escolha dessas variedades para a prática dos alunos-professores serão apresentadas na Fundamentação Teórica.

${ }^{4}$ O termo 'nota reflexiva' é adaptado de Lieff (2003). 
Todos os graduandos concordaram com a inclusão da atividade no curso, e autorizaram a utilização dos conteúdos das suas notas reflexivas em pesquisa. Ficou acordado que as notas reflexivas seriam escritas após cada aula, em casa, e que não teriam um valor avaliativo.

Cento e oito notas reflexivas foram escritas pelos alunosprofessores, distribuídas da seguinte forma: $\mathrm{AP}^{5}=7$; $\mathrm{AP} 2=19$; $\mathrm{AP} 3$ $=8 ; \mathrm{AP} 4=16 ; \mathrm{AP} 5=23 ; \mathrm{AP} 6=19 ; \mathrm{AP} 7=16$.

Ao longo de todo o curso, ao receber as notas reflexivas, eu fazia apenas correções e comentários a respeito de aspectos linguísticos, sem interferir nos conteúdos das mesmas.

\section{Discussão em grupo}

Ao final do curso, após todas as notas reflexivas terem sido entregues, realizei, no último dia de aula, uma discussão em grupo, que foi áudio gravada. Solicitei aos alunos esclarecimentos a respeito de trechos das notas reflexivas que não estavam claros, e deixei-os livres para fazer qualquer comentário que desejassem. Entre os sete alunos que cursaram a disciplina, quatro participaram da discussão: AP2, AP3, AP4 e AP6.

\section{Fundamentação teórica}

Abordarei aqui dois aspectos relacionados ao ensino e aprendizagem da pronúncia do inglês: (1) tipo de pronúncia sugerida por autores para falantes e aprendizes de Inglês Língua Estrangeira (ILE); e (2) fonemas do inglês considerados difíceis para aprendizes brasileiros produzirem.

\subsection{Tipo de pronúncia sugerida para falantes e aprendizes de ILE}

Abercrombie, já em 1956, recomendava que, exceto agentes secretos e aqueles que pretendem ser professores de ILE, "a maioria

${ }^{5}$ AP refere-se a Aluno-Professor. 
dos outros aprendizes precisam ter uma pronúncia confortavelmente inteligível" (ABERCROMBIE, 1956, p. 37). ${ }^{6} \mathrm{O}$ autor define esse tipo de pronúncia como aquela que pode ser entendida sem que o ouvinte precise fazer muito esforço. Assim como Abercrombie, Kenworthy (1987, p. 3) sugere que, enquanto o objetivo de alguns aprendizes pode ser uma pronúncia semelhante a do nativo, "para a maioria um objetivo mais realista é ter uma pronúncia confortavelmente inteligível”.7 Abercrombie (1956) e Kenworthy (1987), apesar de sugerirem a pronúncia inteligível como alvo a ser atingido pela maioria dos aprendizes, admitem que alguns, incluindo aqueles que desejam ser professores de ILE, devem ter uma pronúncia próxima ou semelhante a do falante nativo do inglês.

O foco na pronúncia do falante nativo do inglês como objetivo a ser atingido por aprendizes é radicalmente desafiado por Jenkins (1996). Segundo a autora, "a pronúncia do falante nativo do inglês não deve mais ser o objetivo no ensino de pronúncia” (JENKINS, 1996, p. 34), ${ }^{8}$ mas sim a inteligibilidade, inclusive para aqueles que desejam ser professores de ILE.

Argumentando que o número de falantes não nativos do inglês atualmente excede o de falantes nativos, e que, por esse motivo, o inglês não pertence mais ao nativo, Jenkins $(1996,2000)$ negligencia a pronúncia do falante nativo como alvo a ser tingido por aprendizes, e põe em dúvida a utilização das variedades RP e GA no ensino da pronúncia do inglês. A autora, baseando-se em dados empíricos, propõe um modelo fonológico para inteligibilidade, chamado Lingua Franca Core (LFC). Esse modelo inclui uma série de aspectos de pronúncia necessários para garantir uma comunicação efetiva entre falantes de ILF, que devem ser focalizados no ensino de pronúncia.

6 "most other language learners need no more than a comfortably intelligible pronunciation"

7 "for the majority of learners a far more reasonable goal is to be comfortably intelligible"

8 "native-like pronunciation of English can no longer be the ultimate goal of teaching" 
A pronúncia inteligível também tem sido defendida por Field (2003), que menciona razões para justificar a inclusão desse tipo de pronúncia como o alvo a ser seguido por aprendizes. Três delas são: (1) somente poucos aprendizes podem adquirir uma pronúncia semelhante à do nativo; (2) há aprendizes que podem desejar falar com um sotaque estrangeiro para "manter a própria identidade pessoal e nacional” (FIELD, 2003, p. 34); e (3) não é realista esperar que professores não nativos adquiram uma pronúncia semelhante à do nativo, uma vez que muitos não têm a oportunidade de adquiri-la.

Com base no ponto de vista dos autores mencionados, a pronúncia sugerida para aprendizes de ILE segue a dicotomia pronúncia inteligível e pronúncia semelhante à do falante nativo do inglês, que tem sido incluída e discutida na literatura há várias décadas. Diante dessa dicotomia, considero necessário justificar aqui a opção pelas variedades linguísticas RP e GA para o estudo do sistema sonoro do inglês e para o treino dos professores em formação inicial no curso de Fonética da Língua Inglesa, contexto deste estudo.

Antes de adotar qualquer variedade linguística em um curso de pronúncia para professores em formação inicial, o ideal seria seguir as aspirações e as necessidades desses alunos. No entanto, como essas aspirações e necessidades são diversas e, provavelmente, mutáveis, optei por adotar as variedades RP e GA, e não o modelo LFC proposto por Jenkins (1996; 2000), deixando claro para os alunos-professores que obter esses sotaques não é condição essencial para que os mesmos possam trabalhar com pronúncia em suas atividades como professores. Duas razões justificam a minha opção por RP e GA.

A primeira está relacionada às objeções por parte de profissionais da área de ensino da pronúncia do inglês ao LFC. Uma das objeções refere-se à confiabilidade do modelo. Estudiosos como Hewings (2001), Deterding (2001) e Keys e Walker (2002) argumentam que há a necessidade de um maior número de dados empíricos para confirmar a confiabilidade do LFC. Além disso, inteligibilidade de pronúncia é

9 "to retain a sense of their own personal and national identity" 
extremamente complexa de ser medida, devido as variáveis envolvidas relacionadas ao falante e ao ouvinte (FIELD, 2003), e, não haver na literatura, até o momento, nenhum modelo fonológico considerado confiável para ser utilizado no ensino da pronúncia.

A segunda razão diz respeito à disponibilidade, ou seja, RP e GA são as variedades linguísticas descritas de forma concisa e coerente em livros que apresentam o sistema sonoro do inglês. Como aponta McArthur (2002, p. 42) o RP "tem provavelmente sido o sotaque mais descrito no mundo" 10 e "continua a ser selecionado e oferecido como uma norma de referência para qualquer discussão em torno do inglês britânico falado (e frequentemente de outras variedades do inglês)" 11 (McARTHUR, 2002, p. 43). Quanto ao GA, o autor menciona que "continua a ser usado por estudiosos e professores de inglês como segunda língua e de inglês como língua estrangeira, especialmente fora dos Estados Unidos" 12 (McARTHUR, 2002, p. 170). ${ }^{13}$

\subsection{Sons do inglês considerados difíceis para aprendizes brasileiros produzirem}

Focalizo aqui, de forma sucinta, grupos de sons do inglês considerados difíceis para aprendizes brasileiros produzirem, e os sons que esses aprendizes produzem devido a essas dificuldades. Alguns deles serão referidos na análise dos dados.

\footnotetext{
10 "has probably been the most described and discussed accent on earth" 11 "continues as a matter of course to be selected or offered world-wide as the reference norm for any discussion of spoken British (and often of other varieties of English)"

12 "continues in use among both language scholars and ESL/EFL teachers, especially outside the US"

${ }^{13}$ Há uma publicação que apresenta sotaques variados de falantes nativos para o treino da percepção da fala rápida, como Streaming Speech (CAULDWELL, 2003), no entanto é dirigida para alunos de nível avançado.
} 
(1) Acentuação de palavras

- O padrão de acentuação da língua inglesa causa dificuldades.

$\mathrm{O}$ vocábulo comfortable tende a ser pronunciado com o acento primário na sílaba '-ta'.

(2) Consoantes

- As três oclusivas /p/, /t/ e / k/ em posição inicial de vocábulos tendem a ser pronunciadas sem aspiração.

- As africadas / t $\int /$ e $/ d z /$ tendem a ser substituídas pelas fricativas $/ \int /$ and $/ 3 /$.

- A fricativa, dental, surda // pode ser produzida como $/ \mathrm{t} /$, /s/ ou /f/, e a fricativa, dental, sonora /ð/ como $/ \mathrm{d} /, \mathrm{z} /$ ou $/ \mathrm{v} /$.

- As nasais $/ \mathrm{m} /, \mathrm{n} / \mathrm{e} / \mathrm{y} /$ podem ser omitidas em posição final de sílabas e vocábulos, causando a nasalização da vogal que as precede.

- A aproximante $/ \mathrm{r} /$ tende a ser pronunciada como $/ \mathrm{h} /$.

(3) Vogais

- As vogais anteriores /ii/ e /I/ podem ser produzidas como $/ \mathrm{i} /$; e as frontais $/ \mathfrak{x} / \mathrm{e} / \mathrm{e} / \mathrm{como} / \varepsilon /$.

- As vogais centrais $/ \Lambda /$ e $/ \mathrm{a} /$ tendem a ser pronunciadas como /a/.

- As vogais posteriores /u:/ e / $/$ podem ser pronunciadas como $/ \mathrm{u} /$.

(4) Inserção de vogal

- A vogal [i] tende a ser adicionada em posição final de vocábulos após as oclusivas, as fricativas /f/, /v/, / / e /3/, as africadas, e em posição inicial antes de grupos consonantais iniciados por $/ \mathrm{s} /$.

\section{Análise e resultados}

Os conteúdos das notas reflexivas e da discussão em grupo, permitiram-me agrupar os dados em 4 categorias. 


\subsection{Descoberta de novas formas de pronunciar consideradas 'corretas'}

O aspecto mais recorrente, mencionado em $90 \%$ das notas reflexivas ${ }^{14}$, é relacionado ao fato dos alunos-professores terem descoberto formas de pronunciar diferentes das que costumavam produzir, e considerarem essas formas 'corretas', como mostram os excertos a seguir:

AP5 "Also in this class I discovered how is the correct way to pronounce the word "ones", I can say, with sure, that I have pronounced this word wrong for a long time" (Nota Reflexiva 6)

AP6 "It's becoming common to discover English sounds that I thought I pronounced correctly but I didn't. The approximant $/ \mathrm{r} /$, for example that I pronounced /h/" (Nota Reflexiva 11)

Como mostram os excertos, duas novas formas de pronunciar, o vocábulo 'ones' e a fricativa $/ \mathrm{h} /$ ao invés da aproximante $/ \mathrm{r} /$, foram descobertas por AP5 e AP6 respectivamente. Considero que essas descobertas são relevantes e necessárias durante um curso de pronúncia, e evidenciam um aprimoramento por parte desses alunos-professores. No entanto, a crença de que essas novas formas de pronunciar são as 'corretas' é equivocada. Por essa razão, quando a mesma era mencionada oralmente em sala de aula, procurava explicar que não há forma 'correta' de pronunciar, mas sim uma norma de referência que precisamos ter para estudar o sistema sonoro de qualquer língua, sem que isso signifique uma depreciação de qualquer outra norma.

A fim de evidenciar o que explicava, antecipei a terceira parte do curso, que seria abordada após o término do estudo de todo o sistema sonoro do inglês, que focaliza atividades práticas de percepção de outros sotaques da língua inglesa: o escocês, o irlandês e o indiano (ver Metodologia). Os alunos-professores foram solicitados a distinguir características desses sotaques, e uma discussão dessas características

${ }^{14}$ As notas reflexivas não foram editadas. 
foi feita com base em Wells (1998) e McArthur (2002). Essa discussão, no entanto, não mudou a crença da pronúncia 'correta', já que alguns alunos continuaram fazendo referência a essa forma, mesmo sutilmente, como mostra o trecho de AP4:

AP4 "I feel like I don't know how to pronounce the word singer anymore. That's funny because now I know the "right" pronunciation" (Nota Reflexiva 9)

AP4 usa aspas quando menciona o vocábulo "right", tentando, talvez, não assumir a autoria do termo. Considero que a crença de que existe uma forma correta de pronunciar foi mantida, não só por AP4, mas também por outros alunos-professores, que continuaram a se referir nas notas reflexivas a essa forma. A manutenção dessa crença pode indicar a dificuldade que professores-formadores podem ter ao tentarem mudar, em sala de aula, crenças de professores em formação inicial.

\subsection{Dificuldades relacionadas ao sistema sonoro do inglês}

Foi possível identificar uma dificuldade recorrente relacionada ao grupo de sons consonantais: a discriminação entre a fricativa dental $/ \theta /$ e a fricativa lábio-dental /f/. Essa discriminação ocorreu em uma atividade prática de percepção, em que os alunos-professores foram solicitados a discriminar entre as fricativas dentais $/ \theta / \mathrm{e} / ð / \mathrm{e}$ os pares de fricativas /f/ / V/ e /s/ /z/, ${ }^{15}$ que aprendizes brasileiros tendem a substituir por terem dificuldades em pronunciar as fricativas dentais (ver Fundamentação Teórica). Nos excertos, a seguir, os participantes fazem referência a essa dificuldade:

AP2 "It ((a atividade $))^{16}$ helped me to realize that I'm very good in distinguishing $/ ð /$ from $/ \mathrm{z} /$, and $/ \theta /$ from $/ /$, however

${ }^{15}$ Esta atividade foi extraída de O’Connor e Fletcher (1989, p. 76).

${ }^{16}$ Normas usadas para transcrição, com base em Preti (2003): (()) comentários do transcritor; ? interrogação; ... qualquer pausa; (...) indicação de que a fala foi tomada; MAIÚSCULA entoação enfática.. 
when it comes to the difference between $/ \theta /$ and $/ \mathrm{f} / \mathrm{I}$ have some problems" (Nota Reflexiva 5)

AP7 "For me, some distinguishes of the exercises were easy like $/ \theta /, / \mathrm{s} /, /$ / and $/ \mathrm{z} /$, but the distinguish between $/ \theta /$ and $/$ f/ was very difficult" (Nota Reflexiva 5)

A partir dos excertos, é possível perceber que os participantes tiveram mais dificuldades em discriminar a fricativa dental surda $/ \theta /$ da fricativa lábio-dental /f/, do que dos outros pares de fricativas incluídos nos exercícios, como /ð/ de /z/ e / $\theta /$ de /s/. Essa ausência de dificuldade em discriminar os outros pares é relevante, já que, pelo fato das duas fricativas dentais $/ \theta /$ e $/ ð /$ não existirem no sistema sonoro do português, seria esperado que os participantes tivessem dificuldades em discriminar todos os pares.

Considero que a explicação para a dificuldade em discriminar unicamente $/ \theta /$ de $/ \mathrm{f} /$ é difícil de ser fornecida, uma vez que percepção e discriminação de sons em contextos diversos são extremamente subjetivas e individuais. No entanto, com base em um trecho extraído de uma das notas reflexivas de AP1, mostrado a seguir, uma possível explicação pode ser dada:

AP1 "Another problem that I found was the /f/ sound in final position, like how it appears in 'death', this final / $\mathrm{f} /$ sounds to me like a $/ \theta /$ 'cause I hardly can perceive this distinction" (Nota Reflexiva 6)

Com base neste excerto, é possível inferir que a percepção que AP1 costumava ter do 'th' final no vocábulo 'death' era equivocada, ou seja, como /f/ ao invés de / $\theta /$, já que o participante afirma isso: "the /f/ sound in final position, like how it appears in 'death",". O fato de, através do exercício, AP1 não estar mais percebendo esse 'th' final como /f/, mas sim adequadamente como $/ \theta /$, pode ter feito com que AP1 definisse isso como dificuldade. É relevante mencionar que o fato desse participante ter passado a identificar $/ \theta /$ em posição final no vocábulo 'death' evidencia um aprimoramento da sua percepção. 


\subsection{Valorização das atividades de percepção e de produção}

Todos os alunos-professores afirmaram que as atividades de percepção e produção dos sons em palavras, sentenças e em contextos maiores são úteis, como mostram os trechos a seguir:

AP1 "We listen to the production of these phonemes [africadas $\left./ \mathrm{t} \int / \mathrm{e} / \mathrm{d}_{3} /\right]^{17}$ to improve the perception of these sounds and, by repeating the words, we also improved our pronunciation. That was our third step inside the phonetics, let's keep going!" (Nota Reflexiva 3)

AP2 "We just studying the different pronunciations of words in groups, and this is quite interesting given that just saying words in isolation does not make you achieve a good fluency in any language, although it is still a good way to begin" (Nota Reflexiva 19)

Como mostram os trechos, AP1 e AP2 valorizam as atividades de produção e percepção, e AP2, apesar de mencionar a desvantagem de exercícios com palavras isoladas, reconhece que é uma boa forma de iniciar o treino de percepção e produção. Considero, com base no trecho de AP2, que iniciar práticas de percepção e produção com grupos de palavras, ao invés de palavras isoladas, pode trazer muitas dificuldades e, talvez, desmotivação por parte dos alunos-professores.

$\mathrm{Na}$ discussão em grupo, essas atividades também foram comentadas, como mostra o trecho:

AP3 "Especially in the case of vowels that are much more difficult to describe and you ...you have to hear the sounds in words as much as you can to... be able to perceive differences"

A valorização dessas atividades por parte dos alunos-professores ficou evidenciada, tanto nas notas reflexivas como na discussão em

${ }^{17}$ Esta atividade foi extraída de O’Connor e Fletcher (1989, p. 34) 
grupo, apesar das críticas feitas até hoje, e iniciadas já há algum tempo, por pesquisadores que reivindicam abordagens mais amplas de ensino de pronúncia. Essas seriam as denominadas 'top-down', que focalizam aspectos mais significativos da pronúncia na fala corrente, ao invés da prática de sons isolados e de palavras e sentenças descontextualizadas (JONES, 1997).

Concordo com a inclusão em cursos de pronúncia de aspectos comunicativos da fala corrente, mas não assumo uma posição excludente, ignorando, para alunos que estão estudando pronúncia pela primeira vez, a prática da discriminação de sons através de palavras e sentenças isoladas, consideradas técnicas behavioristas de aquisição de língua estrangeira. Considero necessária a inicialização dessa prática para que os alunos possam aprimorar a percepção e produção dos sons do inglês. Após essa prática, aspectos mais comunicativos da pronúncia através da fala corrente devem ser incluídos. O trecho da nota reflexiva de AP2, mostrado anteriormente, confirma isso.

\subsection{Valorização da pronúncia do falante nativo}

Todos os alunos-professores, desde o início do curso, apontaram o falante nativo como modelo a ser seguido, e o desejo de adquirir uma pronúncia semelhante a esse falante, como mostram os trechos a seguir:

AP5 "Another point that I liked in our class is the discussion about English as a world language and if it is necessary to have the "perfect" English. About that I conclude that although is very hard for us to achieve native's accent, as professionals we must follow it" (Nota Reflexiva 2)

AP1 "Most of the time I've got myself repeating phrases of some movies in a way to emphasis the sound production, the plosives and the fricatives and their usage by native English speakers" (Nota Reflexiva 5)

Como mostram os trechos, AP5 conclui que apesar das dificuldades em alcançar o sotaque do nativo, considera que 
profissionais devem seguir esse sotaque, e AP1, demonstrando autonomia, repete frases de filmes tendo como modelo o falante nativo. $\mathrm{Na}$ discussão em grupo, esse desejo continuou a ser mencionado:

AP3 "I just think that in spite of all the ...the intelligibility stuff you know that you should make yourself clear enough to communicate and to be understood... I think that you are learning to speak a language ...it's already a hard procedure ... why not improve enough to... to make yourself as native-like as possible?"

AP2 “I agree with ((menciona o nome de AP3)) everyone every person who wants to learn a foreign language should focus on that to be as native-like as possible ... and for any learner .... a Japanese that learns Portuguese ... the American that learns Spanish ..."

Percebendo que os alunos-professores tinham ideias bem definidas a esse respeito, problematizei a questão durante a discussão em grupo, e solicitei que se posicionassem a respeito do argumento de Field (2003), de que há aprendizes que podem desejar falar com um sotaque estrangeiro para manter a própria identidade nacional (ver Fundamentação Teórica). Três, entre os quatro alunos-professores que participaram da discussão em grupo, responderam que não se consideram perdendo a identidade pelo fato de desejarem falar com um sotaque semelhante a do falante nativo. Segue um trecho da discussão:

AP2 “I don't I don't think that eh speaking English as a native...would make me ...more English than Brazilian...it's like" AP4 (...) "It's just more clear"

AP2 "yeah like ...I'm Brazilian and and and nobody nothing can change it"

AP3 “I mean...I understand I can... see your point but...I don't know I just disagree because...er identity...I don't know...I just think that...yeah maybe it is I don't know 
AP4 (...) "But you can show your identity... in other ways AP2 "yeah for me the accent is not is not ... the only way to show the identity by the language...it's not HOW you say but WHAT you say that shows your identity as a Brazilian, as a man"

Como mostra o trecho, enquanto AP2 e AP4 afirmam que podem mostrar suas identidades como brasileiros de outras formas, AP3 ficou em dúvida e não expressou claramente a sua posição. Esse participante, antes do questionamento sobre identidade, defendeu a pronúncia semelhante a do falante nativo.

Após a discussão, decidi não mais problematizar essa questão, nem, por receio de influenciá-los, expressar meu ponto de vista. A esse respeito, concordo com Timmis (2002, p. 249), quando menciona que o educador vive um dilema: "os professores podem achar algumas das visões expressas pelos alunos acima estranhas, reacionárias, ou inadequadas. Nesse caso, até onde é nosso direito ou responsabilidade reeducar politicamente nossos alunos?"18 Esse argumento é feito pelo autor, quando, ao investigar as atitudes de aprendizes e professores de ILE sobre seguir normas do falante nativo do inglês, obteve como resultado que $67 \%$ dos aprendizes preferem pronunciar como um nativo.

\section{Desdobramentos futuros}

No início do curso, as notas reflexivas foram solicitadas na tentativa de identificar como os alunos-professores se apropriavam da pronúncia do inglês. Além de ter sido possível alcançar esse objetivo, as notas também auxiliaram os participantes na aprendizagem, como mostra trechos extraídos da discussão em grupo:

AP2 "When you're going to to write them ((as notas))...you try to remember everything that you went through in the class...so it helps you to to...to internalise the the content"

18 'Teachers may find some of the views expressed by the students above to be quaint, reactionary, or ill-informed. In that case, how far is it our right or responsibility to politically reeducate our students? 
AP3 "It was a very good experience...because we had the opportunity ...the opportunity to think about what we learned in class and write it down"

Como mostram os trechos, as notas podem ter auxiliado os participantes na aprendizagem, quando os mesmos, ao escrevê-las, revisavam os conteúdos vistos em sala de aula. Se possível, e havendo tempo, na continuidade deste trabalho optarei por solicitar as notas em sala de aula, após os conteúdos terem sido estudados, ao invés de solicitar que as mesmas sejam feitas em casa. Isso pode fazer com que mais alunos-professores escrevam notas reflexivas, já que houve uma disparidade entre o número de notas escritas: enquanto AP1 escreveu apenas sete, AP5 escreveu 23.

Com relação ao aspecto que mudarei no curso, tratarei os alunosprofessores, não só como aprendizes, mas também como professores em formação inicial. Apesar de terem sido solicitados a registrar em suas notas reflexivas como poderiam usar os conteúdos estudados no curso em suas atividades como professores (ver Metodologia), apenas três, entre os sete participantes, fizeram esse registro: AP4 e AP6, que já atuavam como professores, e AP5 que ainda não lecionava. Um trecho de AP4 e AP5 é mostrado a seguir:

AP4 "We discussed the fact that there are no final plosives in Portuguese. I found it helpful to let students understand why Brazilian speakers tend to pronounce vowels after some English words when they shouldn't be pronounced. It would improve student's pronunciation as they become aware to this fact" (Nota Reflexiva 2)

AP5 (( sobre formas de pronunciar palavras gramaticais)) "It is good for me, as a future teacher, to perceive that as early learners start to training that less difficult they will have"

Como mostram os trechos, AP4 afirma que o conteúdo abordado em sala de aula será útil para conscientizar seus alunos de suas formas de pronunciar, e AP5, colocando-se na posição de um futuro professor, e talvez com base em sua experiência como aprendiz 
durante o curso, conscientiza-se de que quanto mais cedo aprendizes iniciem seus treinos com pronúncia, menos dificuldades terão.

O fato dos participantes deste estudo terem se comportado muito mais como aprendizes do que como professores em formação inicial ocorreu, também, em estudo realizado por Santos (2010) que, a investigar o conhecimento metacognitivo sobre a compreensão oral de professores em formação inicial, verificou que apenas a minoria dos participantes tinha consciência de como aplicar atividades de compreensão oral com seus alunos.

$\mathrm{Na}$ discussão em grupo, AP2, que ainda não atuava como professor, expressou sua dificuldade em aplicar os conteúdos com seus futuros alunos:

\begin{abstract}
AP2 "I imagined if...if it...how could I...because there are so so many slight differences and and I don't I don't ...I think it's very it would be very difficult for for a teacher ...for a foreign teacher of English to to explain all those slight differences and phonemes...mainly in in... in vowels ... because there are too many vowels"
\end{abstract}

Considero que posso ter contribuído para que apenas três dos participantes se comportassem, em alguns momentos, como professores em formação inicial, uma vez que, ao preocupar-me apenas com o conteúdo do curso, não discuti as dificuldades que os alunosprofessores poderiam ter para aplicar esses conteúdos com seus alunos. Por essa razão, em um próximo curso, debaterei sobre suas possíveis dificuldades como professores e pedirei que preparem materiais para ensinarem pronúncia.

\title{
Conclusões
}

Este estudo investigou a apropriação da pronúncia do inglês por professores em formação inicial, durante um curso de Fonética, através de dois instrumentos: notas reflexivas e discussão em grupo áudio gravada. As notas reflexivas, em particular, revelaram-se bastante eficazes, uma vez que continham informações valiosas, não só a respeito das necessidades individuais de cada aluno-professor em relação aos 
conteúdos do curso, mas também a respeito de suas expectativas e crenças a respeito da pronúncia do Inglês. Notas reflexivas, portanto, podem ser um instrumento valioso para guiar professores-formadores na elaboração de materiais e atividades durante seus cursos.

\section{Referências}

ABERCROMBIE, D. Problems and principles in language study. London: Longman, 1956.

AVERY, P.; EHRLICH, S. Teaching American English pronunciation. Oxford: Oxford University Press, 1994.

BAPTISTA, B.O. Frequent pronunciation errors of Brazilian learners of English. In: FORTKAMP, M.B.M.; XAVIER, R.P. (Orgs.). EFL teaching and learning in Brazil: theory and practice. Florianópolis: Insular, 2001. p. 223-230.

CAULDWELL, R. Streaming speech: listening and pronunciation for advanced learners of English. Birmingham: Speechinaction, 2003.

COLLIE, J.; SLATER, S. Listening 3. Scotland: Cambridge University Press, 1993.

CRUZ, N.C. The (un)intelligibility of / $\mathrm{k}$ ÂmfÈteibou/ produced by a Brazilian speaker of English. Speak out! Newsletter of the IATELFL Pronunciation SIG, v. 33, p. 9-13, 2005a.

. Minimal pairs: Are they suitable to illustrate meaning confusion derived from mispronunciation in Brazilian learners' English? Linguagem \& Ensino, Pelotas, v. 8, n.2, p. 171-180, 2005b.

. Pronunciation intelligibility in spontaneous espeech of Brazilian learners’ English. Claritas, São Paulo, v. 12, n. 1, p. 121-138, $2006 a$.

Inteligibilidade de pronúncia no contexto de inglês como língua internacional. Intercâmbio, São Paulo, v. 15, 2006b. 
DALTON, C.; SEILDHOFER, B. Pronunciation. Oxford: Oxford University Press, 1995

DETERDING, D. Review of The phonology of English as an international language. Speak out! Newsletter of the IATELFL Pronunciation SIG, v. 27, p. 38-39, 2001.

FIELD, J. The fuzzy notion of 'intelligibility': A headache for pronunciation teachers and oral testers. LATEFL Special Interest Groups Newsletter, p. 35-38, 2003.

HEWINGS, M. Pronunciation tasks. Cambridge: Cambridge University Press, 1991.

. Review of The phonology of English as an international language. ELT Journal, Oxford, v. 55, n. 3, p. 327-329, 2001.

JENKINS, J. Changing priorities. Speak out! Newsletter of the IATEFL Pronunciation SIG, v. 18, p. 33-40, 1996.

The phonology of English as an international language: new norms, new goals. Oxford: Oxford University Press, 2000.

JONES, R.H. Beyond "Listen and repeat": Pronunciation teaching materials and theories of second language acquisition. System, v. 25, n. 1, p. 103-112, 1997.

KENWORTHY, J. Teaching English pronunciation. London: Longman, 1987.

KEYS, K.; WALKER, R. Ten questions on The phonology of English as an international language. ELT Journal, Oxford, v. 56, n. 3, p. 298302, 2002.

LESSA, A.B.C.T. A ortografia como um fator de interferência da pronúncia do inglês como lingua estrangeira. 1985. 164 p. Dissertação (Mestrado em Linguística Aplicada) - Pontifícia Universidade Católica de São Paulo, São Paulo. 1985. 
LIEFF, C.D. O ensino da pronúncia do inglês numa abordagem reflexiva. In: CELANI, M.A.A. (Org.) Professores e formadores em mudança: relato de um processo de reflexão e transformação docente. Campinas: Mercado de Letras, 2003. p. 107-117.

; NUNES, Z.A. English pronunciation and the Brazilian learner: How to cope with language transfer. Speak Out! Newsletter of the IATELFL Pronunciation SIG, v. 12, p. 22-27, 1993.

MASCHERPE, M. Análise comparativa dos sistemas fonológicos do Inglês e do Português. São Paulo: Revista dos Tribunais, 1970.

McARTHUR, T. The oxford guide to world English. Oxford: Oxford University Press, 2002.

O’CONNOR, J. D. Better English pronunciation. Cambridge: Cambridge University Press, 1999.

.; FLETCHER, C. Sounds English. London: Longman, 1989.

PRETI, D. Interação na fala e na escrita. São Paulo: Humanitas, 2003.

REBELLO, J.T. The acquisition of English initial /s/ clusters by Brazilian EFL learners. 1997. 198p. Dissertação (Mestrado em Letras/Inglês) Universidade Federal de Santa Catarina, Florianópolis. 1997.

ROACH, P. English Phonetics and Phonology. Cambridge: Cambridge University Press, 2002.

SANTOS, S.S. Compreensão oral em língua inglesa e conhecimento metacognitivo de professores em formação inicial. 2010. 157p. Dissertação (Mestrado em Linguagem e Ensino) - Universidade Federal de Campina Grande, Campina Grande. 2010.

SCHUMACHER, C.; WHITE, P.L.; ZANETTINNI, M. Guia de pronúncia do inglês para brasileiros. Rio de Janeiro: Elsevier, 2002. 
SILVA, R. A small scale investigation into the intelligibility of the pronunciation of Brazilian intermediate students. Speak Out! Newsletter of the IATELFL Pronunciation SIG, v. 23, p. 19-25, 1999.

SILVA, T.C. Pronúncia do inglês: para falantes do português brasileiro. Belo Horizonte: FALE/UFMG, 2005.

TIMMIS, I. Native-speaker norms and international English: A classroom view. ELT Journal, Oxford, v. 56, n. 3, p. 240-249, 2002.

WELLS, J. C. Accents of English. Cambridge: Cambridge University Press, 1998. 